\title{
Formation of Ultrafine Grained Structure in Plain Carbon Steels Through Thermomechanical Processing
}

\author{
Hossein Beladi, Georgina L. Kelly and Peter D. Hodgson \\ School of Engineering and Technology, Deakin University, Geelong, Australia, VIC 3217
}

In the present study, wedge-shaped samples were used to determine the effect of nominal equivalent strain (between 0 and 1.2 ) and carbon content $(0.06-0.35 \% \mathrm{C})$ on ferrite grain refinement through dynamic strain-induced transformation (DSIT) in plain carbon steels using singlepass rolling. The microstructural evolution of the transformation of austenite to ferrite has been evaluated through the thickness of the strip. The results showed a number of important microstructural features as a function of strain which could be classified into three regions; no DSIT region, DSIT region and the ultrafine ferrite (UFF) grain region. Also, the extent of these regions was strongly influenced by the carbon content. The UFF microstructure consisted of ultrafine, equiaxed ferrite grains $(<2 \mu \mathrm{m})$ with very fine cementite particles. In the centre of the rolled strip, there was a conventional ferrite-pearlite microstructure, although ferrite grain refinement and the volume fraction of ferrite increased with an increase in the nominal equivalent strain.

(Received November 7, 2003; Accepted January 28, 2004)

Keywords: ultrafine ferrite, dynamic strain-induced transformation, plain carbon steels, thermomechanical processing, carbon content

\section{Introduction}

Ultrafine grained structures in plain carbon steels are gaining in popularity amongst research groups around the World as means of cutting the cost of steel production and opening up the window of high band mechanical properties. This new generation of high strength-high toughness steels is recyclable and environmental friendly. There are a number of different approaches to achieve this goal, dynamic straininduced transformation (DSIT) combined with rapid cooling is a simple and practical route to produce ultrafine ferrite grains (UFF) as small as $1-2 \mu \mathrm{m} .^{1-3)}$

The DSIT exhibits a general insensitivity to variations in chemistry and could therefore be applied to the full range of steels. ${ }^{4)}$ This process involves a strain being applied to the metastable austenite, i.e. between the $A e_{3}$ and $A r_{3}$ temperature range (equilibrium and continuous cooling temperatures for austenite to ferrite transformation, respectively). ${ }^{5)}$ There is a critical condition to produce UFF through the DSIT route which could vary with thermomechanical processing history as well as steel composition. The reduction required for UFF formation through DSIT is quite high, typically more than $40 \%$ in single pass-rolling. ${ }^{3,4)}$ The ultimate goal of the present work is to evaluate the effect of carbon content in conjunction with strain on the ferrite transformation characteristics through the strip thickness and detect the critical strain for DSIT and UFF formation in plain carbon steels.

\section{Experimental Procedure}

The composition of steels used in this study is given in Table 1. All steels are plain carbon steels with different carbon content. The hot rolling facilities, which have been used in this study, include a laboratory mill with rolls of $365 \mathrm{~mm}$ diameter, a rolling speed of $15 \mathrm{rpm}$, a preheating resistance furnace and a fluid bed furnace with maximum working temperature of 1300 and $1100^{\circ} \mathrm{C}$, respectively. The wedge samples were machined to an overall size of $140 \mathrm{~mm}$ $\times 50 \mathrm{~mm} \times 8 \mathrm{~mm}$ with an angle of about $4^{\circ}$ (Fig. 1).

Figure 2 shows the thermomechanical processing cycles, that were applied to perform the single-pass hot rolling. The specimens were soaked at a given austenitization temperature for $15 \mathrm{~min}$., resulting in austenite grain size of greater than $120 \mu \mathrm{m}$ (Table 1). The samples were reheated in stainless steel foil bags to prevent excessive oxidation. Then, the wedge samples were rapidly placed in the fluid bed furnace at the $\mathrm{Ae}_{3}+5^{\circ} \mathrm{C}$ temperature for five minutes to stabilize the temperature for all thicknesses of the wedge sample and to avoid any temperature gradient through the thickness. Afterwards, the specimens were passed through the rolls at a given

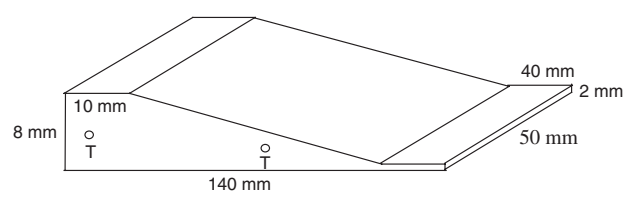

Fig. 1 Wedge specimen (T: Thermocouple position).

Table 1 The chemical composition of steels (in mass \%).

\begin{tabular}{ccccccccccc}
\hline Steel & $\% \mathrm{C}$ & $\% \mathrm{Si}$ & $\% \mathrm{Mn}$ & $\% \mathrm{Al}$ & $\% \mathrm{P}$ & $\% \mathrm{~S}$ & $A e_{3}\left({ }^{\circ} \mathrm{C}\right) *$ & $T_{\text {def }}\left({ }^{\circ} \mathrm{C}\right)$ & $T_{\mathrm{a}}\left({ }^{\circ} \mathrm{C}\right)$ & $\mathrm{d} \gamma(\mu \mathrm{m})$ \\
\hline $\mathrm{A}$ & 0.06 & 0.06 & 0.21 & 0.037 & 0.011 & 0.013 & 880 & $875 \pm 5$ & 1100 & $>120 * *$ \\
\hline B & 0.16 & 0.16 & 0.59 & 0.005 & 0.017 & 0.013 & 845 & $840 \pm 5$ & 1200 \\
\hline $\mathrm{C}$ & 0.35 & 0.26 & 0.82 & 0.03 & 0.012 & 0.003 & 795 & $790 \pm 5$ & 1200 \\
\hline
\end{tabular}

* The $\mathrm{Ae}_{3}$ temperatures were calculated using the ChemSage program.

$* * \mathrm{~d} \gamma$ could not be measured because of ultra low carbon content. 


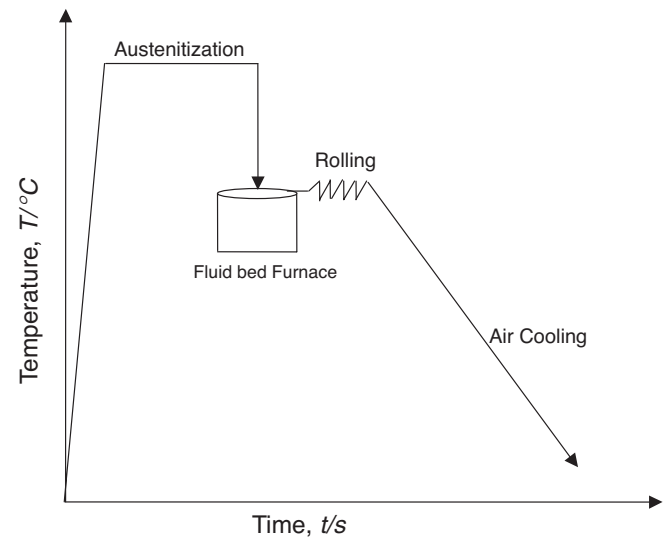

Fig. 2 Schematic representation of heat treatment and thermomechanical schedule.

temperature (Table 1) to achieve a strip with a final thickness of $\sim 2 \mathrm{~mm}$. The temperature of the specimens was measured continuously during the test by $\mathrm{N}$-type thermocouples, inserted at different positions in the sides of samples (Fig. 1). Furthermore, the surface temperature was measured by a pyrometer throughout the experiment. After deformation, the rolled strips were air cooled to room temperature.

The dimension of the wedge sample was designed based on the rolling mill capacity and to minimize the lateral spreading during rolling. However, there was still some spreading during rolling for the reductions greater than $50 \%$. Therefore, the width of the specimen was also measured at each location after rolling. Equation (1) was then used to estimate the equivalent strain along the rolled strip taking into account the spread. ${ }^{6}$

$$
\bar{\varepsilon}=\left[\frac{4}{3}\left(\varepsilon_{t}^{2}+\varepsilon_{w}^{2}+\varepsilon_{t} \varepsilon_{w}\right)\right]^{1 / 2}
$$

where $\varepsilon_{t}=\ln \left(t_{0} / t_{f}\right)$ and $\varepsilon_{w}=\ln \left(w_{0} / w_{f}\right)$ are strains in the thickness $t$ and width $w$ dimensions, in which the subscripts 0 and $f$ refer to original and final thicknesses and widths, respectively.

Metallographic observations were made on the normal direction-rolling direction plane at a depth of between $0.1-$ $0.15 \mathrm{~mm}$ below the surface of the rolled strips and at the mid thickness. The ferrite volume fraction was determined by point counting. In this study, only the volume fraction of polygonal ferrite was considered. The mean ferrite grain size was determined using the mean linear intercept method.

\section{Results}

The final thickness of the deformed strips was typically in the range from 2 to $2.7 \mathrm{~mm}$. The microstructures of all rolled samples were inhomogeneous through the strip thickness. In addition, the ferrite transformation characteristics in the surface layer varied not only with the strain, but also with the steel composition (carbon content). Based on this observation, the ferrite transformation characteristics could be classified into three regions as a function of strain in the surface layer (Fig. 3).

At regions that underwent low reductions, the micro- (a)

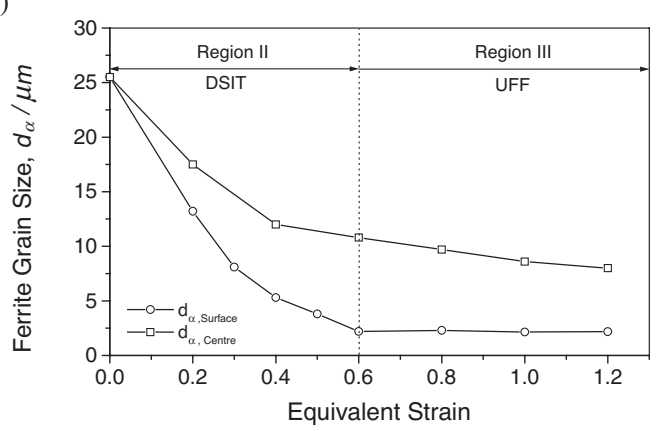

(b)

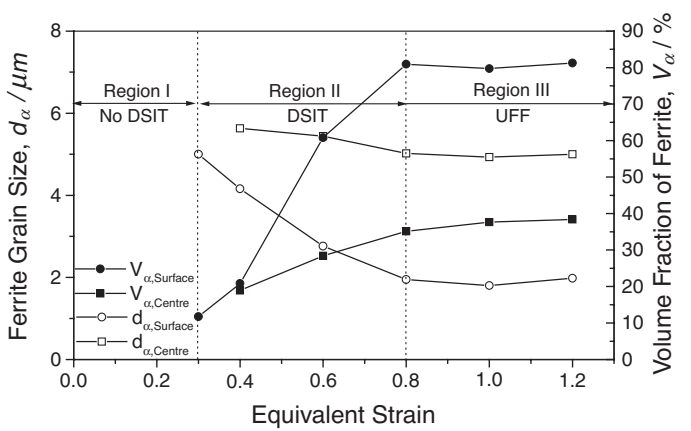

(c)

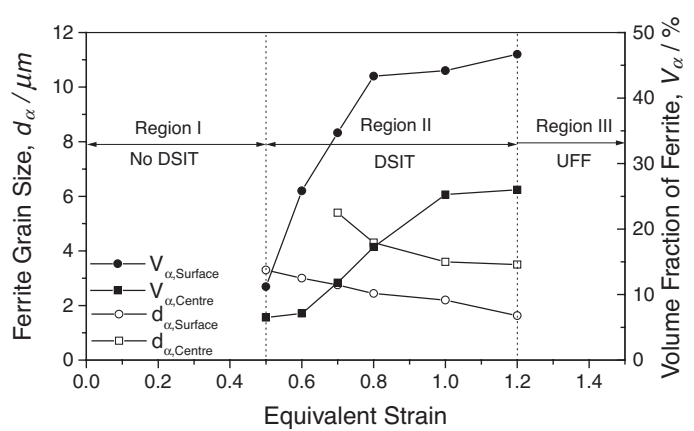

Fig. 3 Ferrite grain size and volume fraction of ferrite as a function of equivalent strain in plain carbon steels through single-pass rolling: (a) steel A, (b) steel B and (c) steel C.

structure near the surface was indistinguishable from that at the centre of the plate; only a few polygonal ferrite grains (less than 0.1 volume fraction of microstructure) formed on prior austenite grain boundaries, the rest of the microstructure being a mixture of non-polygonal ferrite (Widmanstätten and acicular) and pearlite (hereafter called region I, Fig. 4a). The result suggested that the required strain was not sufficient for dynamic strain-induced transformation to produce polygonal ferrite grains. This region was extended to higher strains with increasing in carbon content and was not present in steel A with the low carbon content (Fig. 3).

For locations corresponding to region II, the volume fraction of polygonal ferrite significantly increased throughout the thickness with an increase in the strain for all steels (Fig. 3). The ferrite grain size was significantly refined in the surface layer, although some acicular ferrite was still present in the microstructure (Figs. 3 and $4 b$ ). There were also some carbide particles on ferrite grain boundaries. The volume fraction of carbide increased with an increase in the strain and carbon content. These carbides were also arranged in elongated and narrow bands for steels $\mathrm{B}$ and $\mathrm{C}$; their orientation did not appear to have any specific relationship 

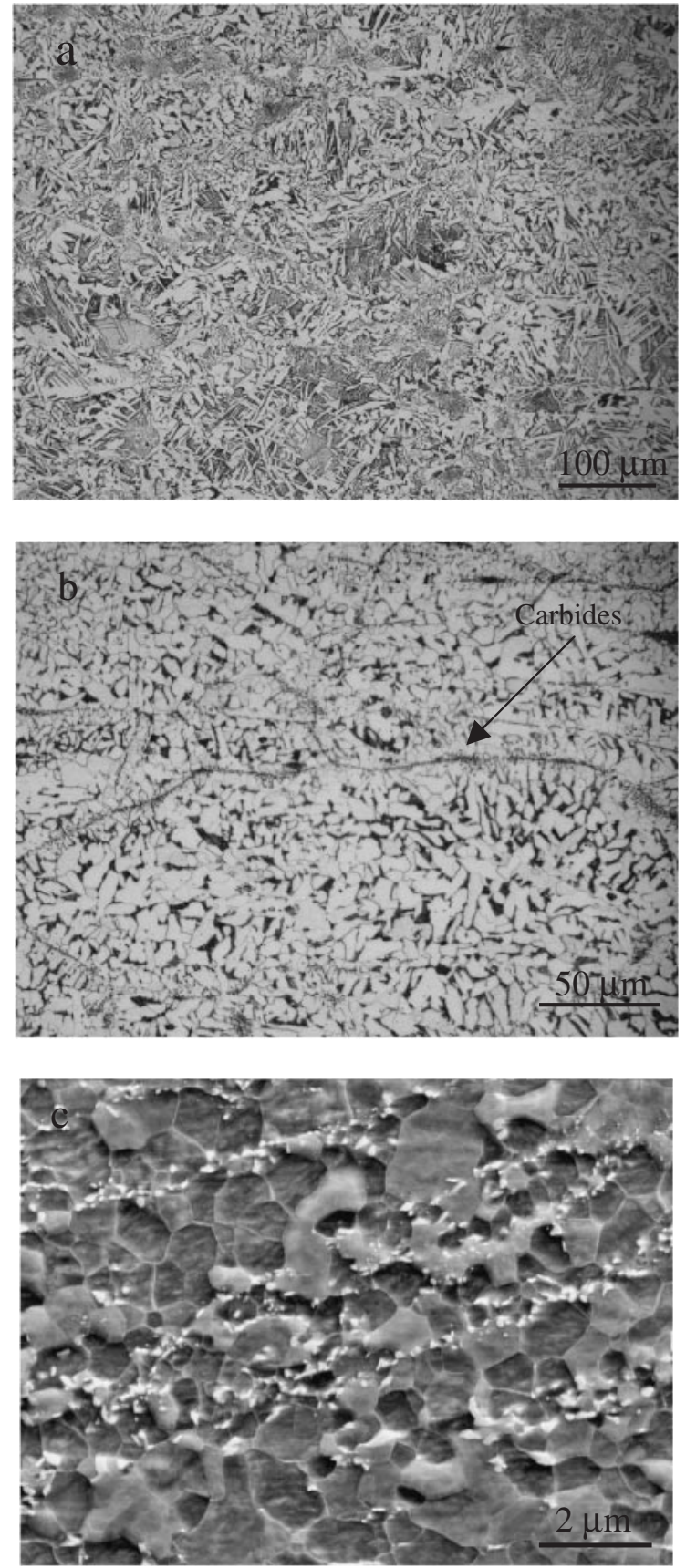

Fig. 4 The surface microstructure of steel $\mathrm{B}$ at different equivalent strains: (a) 0 , (b) 0.6 and (c) 0.8 .

with the rolling direction (indicated by the arrow in Fig. 4b). As-quenched microstructures in region II consisted of polygonal ferrite grains mainly decorating prior austenite grain boundaries and intragranularly nucleated. This suggests dynamic strain-induced transformation of ferrite occurred during deformation. This region was also extended with an increase in the carbon content (Fig. 3).

Beyond a critical strain condition, the volume fraction of ferrite and the ferrite grain size of the surface layer did not change significantly with an increase in the strain for all steels (region III in Fig. 3). The microstructures consisted of fully polygonal ferrite grains, as small as $1-2 \mu \mathrm{m}$ in size, with carbide particles on ferrite grain boundary (there were also very fine pearlite and carbide bands for steels B and C, Fig.
Table 2 The critical strains for DSIT and UFF formation.

\begin{tabular}{cccc}
\hline Steel & $\% \mathrm{C}$ & $\varepsilon_{\mathrm{C}, \mathrm{DSIT}}$ & $\varepsilon_{\mathrm{C}, \mathrm{UFF}}$ \\
\hline $\mathrm{A}$ & 0.06 & $-\ldots .-$ & 0.6 \\
\hline $\mathrm{B}$ & 0.16 & 0.3 & 0.8 \\
\hline $\mathrm{C}$ & 0.35 & 0.5 & 1.2 \\
\hline
\end{tabular}

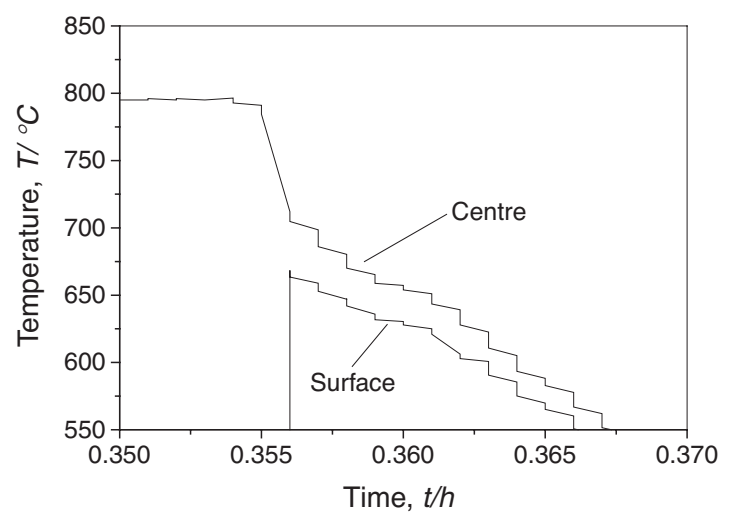

Fig. 5 Cooling curve of centre and surface of a location corresponding to plate thickness of $8 \mathrm{~mm}$ during thermomechanical processing.

4c). However, this strain was significantly increased with an increase in carbon content. The UFF surface layer generally penetrated to about $1 / 4$ of the total thickness.

The required strain for transition from one region to another one in the surface layer was described as a critical strain in this study. Hence, there were two critical strains; dynamic strain-induced transformation $\left(\varepsilon_{\mathrm{C}, \mathrm{DSIT}}\right)$ and ultrafine ferrite formation $\left(\varepsilon_{\mathrm{C}, \mathrm{UFF}}\right)$. These strains are summarized in Table 2 for all steels. The critical strain for both transitions increased significantly with an increase in carbon content.

In the centre of rolled strip, the microstructures were conventional ferrite and pearlite (or carbide in steel A). The ferrite grain size decreased with an increase in the strain for all steels (Fig. 3). However, the change in grain size with increasing nominal strain was much lower in the centre than the surface. This is because the amount of undercooling and strain is different at the surface compared with the centre of strip. For example, at the location corresponding to an equivalent strain of 1.2 , the undercooling at the surface and the centre was $\sim 120^{\circ} \mathrm{C}$ and $80^{\circ} \mathrm{C}$, respectively (Fig. 5). Furthermore, it has been shown that the strain at the surface is more than three times that at the centre of strip through finite element modeling of strip rolling under heavy shear. ${ }^{7)}$ In addition, the ferrite grain size decreased with an increase in the carbon content at a given strain (Fig. 3).

\section{Discussion}

The single-pass rolling and subsequent air cooling of the wedge samples showed a number of important microstructural features as a function of strain which could be classified into three regions. However, the extent of regions varied significantly with the carbon content.

Region I: no dynamic strain-induced transformation

It is well known that the formation of non polygonal 
Table 3 The surface temperature of rolled strip at the exit point of rolls at different initial thicknesses.

\begin{tabular}{ccccc}
\hline & \multicolumn{2}{c}{$\begin{array}{c}\text { Initial thickness of } \\
\text { ( }\end{array}$} & \multicolumn{2}{c}{ Initial thickness of } \\
$T_{\text {def }}\left({ }^{\circ} \mathrm{C}\right)$ & $T_{\mathrm{s}}\left({ }^{\circ} \mathrm{C}\right)^{*}$ & $\Delta T\left({ }^{\circ} \mathrm{C}\right)$ & $T_{\mathrm{s}}\left({ }^{\circ} \mathrm{C}\right)^{*}$ & $\Delta T\left({ }^{\circ} \mathrm{C}\right)$ \\
\hline $875 \pm 5$ & 739 & 136 & 697 & 178 \\
\hline $840 \pm 5$ & 713 & 127 & 669 & 171 \\
\hline $790 \pm 5$ & 668 & 122 & 625 & 165 \\
\hline
\end{tabular}

*The surface temperature

phases is promoted with increasing cooling rate ${ }^{8)}$ and carbon content. ${ }^{9)}$ The latter is confirmed by this study since the volume fraction of non polygonal ferrite decreased with a decrease in carbon content at a given condition (steel $\mathrm{A}$ is fully polygonal ferrite even at the strain free condition).

There is an increasing tendency for ferrite to grow from grain boundaries as plates (Widmanstätten morphology) with increasing cooling rate. The rapid cooling is occurred by conduction of the cold rolls in the surface of strip in singlepass rolling; the surface temperature drops $\sim 120-180^{\circ} \mathrm{C}$ during rolling depending on the initial thickness and deformation temperature (Table 3). At regions that underwent low reductions, this rapid cooling decreases the temperature to such an extent (i.e. $T_{\mathrm{W}}$; the critical temperature for Widmanstätten ferrite formation ${ }^{8)}$ ) that non polygonal products are promoted after straining. The result suggests that the strain was not sufficient to form the polygonal ferrite rather than non polygonal phase by DSIT in this region.

\section{Region II: dynamic strain-induced transformation}

The DSIT ferrite initially nucleates on the prior austenite grain boundary. ${ }^{10)}$ Therefore, the nucleation of DSIT ferrite at an early stage of transformation retards the formation of austenite grain boundary nucleated non polygonal ferrite phases (i.e. Widmanstätten ferrite) after deformation. Beyond $\varepsilon_{\mathrm{C}, \mathrm{DSIT}}$, the volume fraction of ferrite nucleation sites is increased and extends from the prior austenite grain boundaries into the austenite grain interior with increase in the strain (intragranular nucleation sites). This promotes the volume fraction of polygonal ferrite grains.

It is well known that the DSIT process significantly controls the coarsening of ferrite grains during post deformation cooling. ${ }^{11)}$ This leads to much more effective ferrite grain refinement through DSIT than conventional controlled rolling. However, the amount of coarsening depends on the volume fraction of DSIT ferrite and its distribution at an early stage of transformation. The volume fraction of DSIT ferrite grains increases with an increase in the strain (i.e. increasing the $\mathrm{Ar}_{3}$ temperature) at the early stage of transformation in region II. This increases the impingement of DSIT ferrite grains as a function of the strain at the early stage of transformation, which thereby controls the coarsening of ferrite grains during post deformation cooling. ${ }^{11)}$ This promotes the ferrite grain refinement with an increase in the strain in region II.

\section{Region III: ultrafine ferrite formation}

Beyond a given condition, the volume fraction of polygonal ferrite and ferrite grain size of the surface layer do not change significantly for all steels. The resultant ferrite grain size is as small as $1-2 \mu \mathrm{m}$. Indeed, the coarsening rate is independent of strain in region III. This suggests that the volume fraction of DSIT ferrite and its distribution at the early stage of transformation does not alter significantly

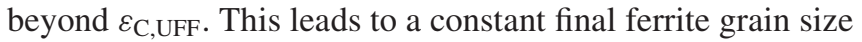
in this region.

Although the current work confirms that UFF formation is independent of steel composition, the critical strains for DSIT ferrite and UFF formation are significantly altered by carbon content. It is proposed that the effect of carbon content in postponing the critical strains for DSIT and UFF formation could be explained by the stacking fault energy (SFE) value, the prior austenite grain size and the chemical driving force for dynamic ferrite transformation.

Although, the SFE parameter has been shown to have a strong influence on the behaviour of metals and alloys during deformation, ${ }^{12)}$ Charnock et al. ${ }^{13)}$ proved the carbon content (0.005-0.83\% mass C) does not have a significant effect on the SFE.

It is well established that the number of intragranular defects formed during deformation is raised by increasing the austenite grain size. ${ }^{14)}$ A recent study ${ }^{10)}$ has shown that the $\varepsilon_{\mathrm{C}, \mathrm{DSIT}}$ significantly decreased (from 0.5 to 0.1 ) with an increase in the prior austenite grain size (from 14 to $80 \mu \mathrm{m}$ ), this had a slight change on $\varepsilon_{\mathrm{C}, \mathrm{UFF}}$. Since the prior austenite grain size is higher than $120 \mu \mathrm{m}$ in this study, it is unlikely the prior austenite grain size could have a significant influence on these critical strains.

During dynamic strain-induced transformation of austenite to ferrite, the driving force for nucleation and growth of ferrite in the austenite region comes from the deformation (i.e. reduction) and the composition. Decreasing the carbon content increases the equilibrium transformation temperature and the $\mathrm{Ar}_{3}$ for low carbon steels. Hence, for a given state of the austenite, it would be expected that transformation of ferrite will occur at a higher temperature and faster rate for a lower carbon content. A simple explanation for DSIT is that the $A r_{3}$ increases during deformation with increasing strain until reaches the temperature of the deformation. From this it would be expected that a higher $\mathrm{Ar}_{3}$ before deformation will allow this condition to be met at a lower strain. Hence, it is likely that with an increase in carbon content, the reductions required for dynamic ferrite transformation and later UFF formation would be increased (i.e. nucleation and growth of ferrite). This supports the decrease in the critical strain for UFF formation in steel A from 1.2 (for steel C) to 0.6.

\section{Conclusions}

(1) There were a number of important microstructural features as a function of strain through single-pass rolling and subsequent air cooling of the wedge samples. Based on the observation, three regions were determined as follows:

Region I: no dynamic strain-induced transformation Region II: dynamic strain-induced transformation Region III: ultrafine ferrite grain formation

(2) There were two critical strains for DSIT ferrite and ultrafine ferrite formation. 
(3) The carbon content has shown a significant effect on these critical strains. The critical strains were postponed to a higher value with an increase in the carbon content.

(4) The effect of carbon content in postponing the critical strains for DSIT and UFF formation could be explained by the chemical driving force for dynamic ferrite transformation.

\section{Acknowlagements}

This work was supported by the Australian Research Council. The technical assistance of J. Whale and R. Pow is gratefully acknowledge. H. Beladi also acknowledges the support of a Deakin University research scholarship.

\section{REFERENCES}

1) R. Priestner: Thermomechanical Processing of Microalloyed Austenite, ed. by A. J. DeArdo, G. A. Ratz and P. J. Wray, (TMS-AIME, Warrendale, PA, 1981) 455-466.
2) J. H. Beynon, R. Gloss and P. D. Hodgson: Mater. Forum 16 (1992) 3742.

3) P. D. Hodgson, M. R. Hickson and R. K. Gibbs: Scr. Mater. 40 (1999) 1179-1184.

4) M. R. Hickson, R. K. Gibbs and P. D. Hodgson: ISIJ Int. 39 (1999) 1176-1180.

5) H. Yada, C. M. Li and H. Yamagata: ISIJ Int. 40 (2000) 200-206.

6) R. Priestner, Y. M. Al-Horr and A. K. Ibraheem: Mater. Sci. Technol. 18 (2002) 973-980.

7) X. J. Zhang, P. D. Hodgson and P. F. Thomson: Mater. Process. Technol. 60 (1996) 615-619.

8) D. A. Porter and K. E. Easterling: Phase Transformations in Metals and Alloys, (2nd ed., London, Chapman \& Hall, 1992).

9) R. F. Mehl and C. A. Dube: Phase Transformations in Solids, (John Wiley, New York, 1951).

10) H. Beladi, G. L. Kelly, A. Shokouhi and P. D. Hodgson: Mater. Sci. Eng. A 367 (2004) 152-161.

11) H. Beladi, A. Zarei-Hanzaki, G. L. Kelly and P. D. Hodgson: Mater. Sci. Technol. 20 (2004) 213-220.

12) B. Bay, N. Hansen, D. A. Hughes and D. Kuhlmann-Wilsdorf: Acta Metall. Mater. 40 (1992) 205-219.

13) W. Charnock and J. Nutting: Metal Sci. J. 1 (1967) 123-127.

14) R. Bengochea, B. Lopez and I. Gutierrez: ISIJ Int. 39 (1999) 583-591. 